\title{
SHORELINE MONITORING BY GNSS-PPP AIMING TO ATTENDANCE THE LAW 14.258/2010 FROM PERNAMBUCO STATE, BRAZIL
}

\author{
HAROLDO ANTONIO MARQUES ${ }^{1}$ - ORCID: 0000-0001-9535-8723 \\ RODRIGO MIKOSZ GONÇALVES ${ }^{2}$ - ORCID: 0000-0002-5066-1910 \\ ALEX DA SILVA ARAUJO ${ }^{2}$ - ORCID: 0000-0002-0608-3551 \\ PEDRO DE SOUZA PEREIRA ${ }^{3}$ - ORCID: 0000-0001-6903-9155
}

HEITHOR ALEXANDRE DE ARAUJO QUEIROZ ${ }^{4}$ - ORCID: 0000-0002-9537-9847

${ }^{1}$ Instituto Militar de Engenharia - IME, Seção de Engenharia Cartográfica, Rio de Janeiro, RJ, Brazil. E-mail: haroldoh2o@gmail.com

${ }^{2}$ Universidade Federal de Pernambuco-UFPE, Departamento de Engenharia Cartográfica, Programa de Pós-Graduação em Ciências Geodésicas e Tecnologias da Geoinformação, Recife, PE, Brazil.

E-mail: rodrigo.mikosz@ufpe.br

${ }^{3}$ Universidade Federal de Santa Catarina-UFSC, Coordenadoria Especial de Oceanografia, Florianópolis - SC, Brasil.

E-mail: psppraias@gmail.com

${ }^{4}$ Instituto Nacional do Semiárido-INSA, Setor de Geoprocessamento, Campina Grande - PB, Brasil. E-mail: heithorqueiroz@gmail.com

Received in $25^{\text {th }}$ September 2018

Accepted in $7^{\text {th }}$ January 2019

\begin{abstract}
:
The geodetic shoreline positioning has socioeconomic importance due to decision-making support related to the coastal zone. The Pernambuco state, Brazil, has established a state law no. 14.258/2010 sanctioned as part of Coastal Zone Management State Policy. The state act no. 42.010/2015 enacted the baseline information for Pernambuco shoreline. Considering that the shoreline mapping benefits from GNSS positioning using relative or absolute methods, the absolute PPP was the choice for legislation support. Therefore, the aim of this work is to depict about the Pernambuco state law and analyze the kinematic PPP accuracy applied to shoreline monitoring in order to attend the state act. The relative GNSS method was adopted as reference to assess the PPP accuracy for the Pernambuco shoreline. The analyses for each sector involved approximately one hour of kinematic GNSS data and the results indicate horizontal positioning accuracy around $0.50 \mathrm{~m}$ after PPP convergence period. Several PPP re-initialization has been detected, however, points considered outliers are removed from the final product. For this reason, recommendations are provided to improve the positioning applied for coastal zone monitoring. Although, the carried out experiments shows that PPP can be adopted as a practical tool to support the Pernambuco Coastal Zone Management.
\end{abstract}

Keywords: GNSS Positioning; Shoreline; Integrated Coastal Zone Management

How to cite this article: MARQUES, H.A., GONÇALVES, R.M., ARAUJO, A.S., PEREIRA, P.S. and QUEIROZ, H.A. Shoreline Monitoring by GNSS-PPP Aiming to Attendance the Law 14.258/2010 from Pernambuco State, Brazil. Bulletin of Geodetic Sciences, 25(2): e2019012, 2019. 


\section{Introduction}

The shoreline is the boundary between the continent and the adjacent portion of the sea where there is no effective marine action at the maximum range of the waves (Suguio, 1992; Awange, 2012; Asib et. al, 2018). The shoreline monitoring is underlying for several regions around the world and it plays an important socioeconomic and environmental role, since the monitoring allows evaluating coastal erosion processes related to sediment transportation that often leads to coastal zone settlement problems (Goncalves et al., 2012a; Goncalves et al., 2012b; Mendonca et al. 2014).

The Integrated Coastal Zone Management (ICZM) requires information from shoreline monitoring to take actions about recovering and marine areas preservation, highlighting the importance of climate change research applied to coastal zones (CENCl et al., 2018; BRACS et al., 2016; NATESAN et al., 2015). Thus, shoreline monitoring becomes essential information as models input able to evaluate coastal erosion vulnerability. For instance, from shoreline change rate (meters/year), it is possible to detect the behavior of a specific beach sector describing, for e.g., if it is stable or even facing coastal erosion problems.

The coastal zone management is extremely important and consequently, authorities concern about present and future actions, particularly about the natural resources that provide support for life and opportunity for economic and touristic developments around coastal countries (Clark et al., 1998).

In Brazil, the Law n. 7.661 from May 16 of 1988 shows the coastal monitoring commitment. Such law established the National Coastal Management Plan (PNGC) as an integral part of the National Environmental Policy (PNMA) and the National Policy for Marine Resources (PNRM), aiming to guide the rational use of resources in the coastal zone and being a legal framework showing how to protect and preserve the environment in a sustainable way.

The Pernambuco state government published in December 23 of 2010 the Coastal Management Law under the number 14.258 aiming the coastal environmental preservation and consequently appreciation. The coastal zone concentrates great economic and touristic potential and the State law in the chapter $V$ and article 10 proposes that in urbanized areas it will not be allowed any kind of new buildings construction, nor urbanization or any kind of soil utilization taking account a distance of 33 meters (considered as non-aedificandi) from the shoreline.

In August 04 of 2015, it was established the act number 42.010 which showed the Global Navigation Satellite System (GNSS) positioning for Pernambuco state shoreline delimitation by taking account the maximum high spring tide as shoreline indicative. In addition, the second act recommend intervals of five years (temporal resolution) for shoreline monitoring and update, considering that such period could be variable depending on the climate change and local dynamic.

Considering the state law, the Pernambuco Environment and Sustainability Secretariat (SEMAS) requested support from Federal University of Pernambuco (UFPE) to perform the shoreline monitoring through GNSS in a kinematic surveying mode aiming to map the entire Pernambuco coastal zone.

The choice for a specific geodetic technique considering the coastal monitoring is not a trivial task due to several factors, for e.g., the shoreline extension, feasibility, operational, financial 
costs and positional accuracy (Awange, 2012; Goncalves 2010). Some applied techniques could be cited, as for example, remote sensing or traditional photogrammetry using airplanes or even nowadays using Unmanned Aerial Vehicles (Moussaid et al., 2015; Turner et al., 2016).

Concerning the GNSS positioning, it is possible to carry out absolute or relative positioning. In Brazil, the GNSS data provided by the Brazilian active network (Brazilian Continuous Monitoring Network - RBMC) support the relative positioning realization. However, there are only one GNSS station located at Recife, capital of Pernambuco state, providing long baselines (up to $200 \mathrm{~km}$ ) considering the extremes of the state in the northern and southern sectors, which can compromise the relative positioning quality. On the other hand, Real Time Kinematic (RTK) method is another option; however, considering the long coastal zone extension, limitations arise due to frequent base receiver repositioning in function of radio communication range. Further details about comparison among RTK, Precise Point Positioning (PPP) and relative kinematic methods regarding supporting coastal monitoring can be seen in Goncalves and Awange (2017). Therefore, the adopted method in this work is the kinematic PPP whereupon only one receiver collects GNSS data providing a higher yield in surveying.

The main objective of this paper is to depict about the state coastal management law (14.258/2010) and to assess the accuracy of kinematic PPP applied to Pernambuco state shoreline monitoring. The GNSS data collected on board by a GNSS receiver (GPS and GLONASS) adapted by an antenna using a quadricycle and tracking the entire coastal zone state were post processed in the kinematic PPP mode. Furthermore, the relative method for a given sample (Recife region) with short baselines provided reference coordinates for accuracy analysis. The paper presents in Section 2 a review on GNSS methods, the methodology and the data used are presented in Section 3. The results and analyses are in Section 5 and conclusions in Section 6.

\section{Review about GNSS Positioning}

The GNSS positioning methods are, generally, divided into absolute and relative. In the absolute, the user needs only one GNSS receiver for surveying and in the relative, two or more receivers acquiring GNSS data simultaneously are necessary as represented in the Figure 1.
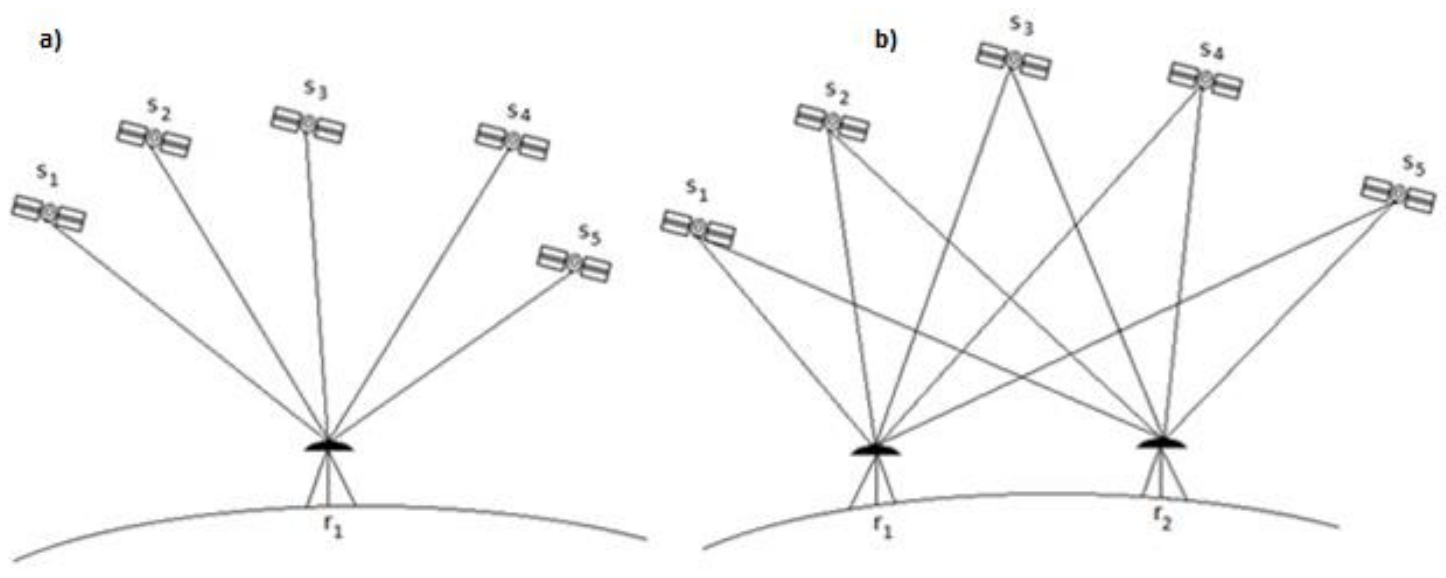

Figure 1 - Representation of absolute (a) and relative positioning (b) 
The specialized literature in geodesy provides detailed description on how to model GNSS errors (Witchayangkoon, 2000; Seeber, 2003; Leick, 2004; Leandro, 2009; Hauschild, 2010), which include satellite orbits, clocks and hardware delays, antennas phase center variations, atmospheric effects (ionosphere and troposphere) and relativity corrections.

Considering kinematic positioning, several problems may occur due to the movement of vehicles affecting the Dilution of Precision (DOP) factor, causing sometimes cycle slips, and loss of satellites signals. The combined effects of orbits, clocks, hardware and other propagated errors, when projected into the satellite receiver direction is denominated User Equivalent Range Error (UERE) or simply User Range Error (SEEBER, 2003).

The total UERE comprises the components of each GNSS system segment: spatial, control and user. The contribution of each UERE component for single or double frequency measurements is passible of analyzes. Normally, the total UERE is assessed based on the Root Sum Square (RSS) of each error source assuming Gaussian distribution. Table 1 shows the contribution of GPS errors in pseudorange measurements considering the Standard Positioning Service (SPS) and Precise Positioning Service (PPS) for a single point positioning (Kaplan and Hegarty, 2006).

Table 1: Contribution of errors in the GPS pseudorange measurements

\begin{tabular}{l|l|c|c}
\hline \multirow{3}{*}{ Segment } & Source of Error & $\begin{array}{c}\text { Typical UERE PPS } \\
\text { Error } 1 \sigma(\mathrm{m})\end{array}$ & $\begin{array}{c}\text { Typical UERE } \\
\text { SPS } \\
\text { Error } 1 \sigma(\mathrm{m})\end{array}$ \\
\hline \multirow{3}{*}{$\begin{array}{l}\text { Spatial/ } \\
\text { Control }\end{array}$} & Broadcast clock & 1.1 & 1.1 \\
\cline { 2 - 4 } & Hardware Delay L1-P(Y)-L1(C/A) & - & 0.3 \\
\cline { 2 - 4 } & Broadcast Orbit & 0.8 & 0.8 \\
\hline \multirow{3}{*}{ User } & Residual lonosphere delay & 0.1 & 7.0 \\
\cline { 2 - 4 } & Residual Troposphere Delay & 0.2 & 0.2 \\
\cline { 2 - 4 } & Receiver Residual & 0.1 & 0.1 \\
\cline { 2 - 4 } & Multipath & 0.2 & 7.1 \\
\hline UERE Total & Total RSS & 1.4 & 0.2 \\
\hline
\end{tabular}

Source: Adapted from Kaplan and Hegarty (2006).

The residual effect appears after the mathematical model application for the measurements corrections. For a single frequency data, Table 1 shows that the dominant error is due to ionosphere layer after the transmitted coefficients application considering the Klobuchar model.

The absolute positioning is very useful for navigation solution and the Precise Point Positioning provides positional estimation with centimeter accuracy. The traditional PPP method involves the application of ionosphere free combination (ion-free), precise orbit and clocks, troposphere estimation and modelling of several errors such as relativity corrections, phasewindup, Ocean Tide Loading, Earth Body Tide, Phase Center Variation for receiver and satellites among others. 
The equations (1) and (2) represents the functional model for the PPP data adjustment involving as parameters the receiver coordinates, receiver clocks, zenithal wet tropospheric delay and ambiguity (Witchayangkoon, 2000; Seeber, 2003; Leick, 2004; Kaplan and Hegarty, 2006; Leandro, 2009; Hauschild, 2010; Marques, et al., 2014):

$$
\begin{gathered}
P R_{I F r}^{s}=\rho_{r}^{s}+c\left(d t_{r}\left(t_{r}\right)-d t^{s}\left(t^{t}\right)\right)+m_{f} Z w d+\varepsilon_{P R_{r}^{s}} \\
\lambda_{I F} \phi_{I F r}^{s}=\rho_{r}^{s}+c\left(d t_{r}\left(t_{r}\right)-d t^{s}\left(t^{t}\right)\right)+\lambda_{I} N_{I F}+m_{f} Z w d+\varepsilon_{\phi_{r}^{s}}
\end{gathered}
$$

Where:

- $\quad P R_{I F r}^{s}$ and $\lambda_{I F} \phi_{I F r} \stackrel{s}{r}$ - refer to ionosphere-free pseudorange and carrier phase (meter), respectively;

- $\quad \rho_{r}^{s}$ - is the geometric distance between receiver $r$ and satellite $\mathrm{s}$;

- $d t_{r}\left(t_{r}\right)$ and $d t^{s}\left(t^{t}\right)$ - are the receiver and satellite clock correction at signal reception time $t_{r}$ and transmission time $t^{t}$, respectively;

- Z Zwd and $m_{f}$ - are wet tropospheric delay in the zenith direction and its mapping function, respectively.

- $N_{I F}$ - is the phase ambiguity;

The mathematical models as presented in equations (1) and (2) are not linear. The linearized equation of type $E\{L\}=A X$ through Taylor expansion for the receiver $r$ and satellite $s_{i}$ can be written as:

$$
E\left\{\left[\begin{array}{c}
\nabla P R_{I F r}{ }^{s i} \\
\nabla \lambda_{I F} \phi_{I F r}^{s i}
\end{array}\right]\right\}=\left[\begin{array}{cccccc}
-\frac{X^{s i}-X_{r}^{0}}{\left(\rho_{r}^{s i}\right)^{0}} & -\frac{Y^{s i}-Y_{r}^{0}}{\left(\rho_{r}^{s i}\right)^{0}} & -\frac{Z^{s i}-Z_{r}^{0}}{\left(\rho_{r}^{s i}\right)^{0}} & 1 & m_{f} & 0 \\
-\frac{X^{s i}-X_{r}^{0}}{\left(\rho_{r}^{s i}\right)^{0}} & -\frac{Y^{s i}-Y_{r}^{0}}{\left(\rho_{r}^{s i}\right)^{0}} & -\frac{Z^{s i}-Z_{r}^{0}}{\left(\rho_{r}^{s i}\right)^{0}} & 1 & m_{f} & \lambda_{I F}
\end{array}\right]\left[\begin{array}{c}
\Delta X_{r} \\
\Delta Y_{r} \\
\Delta Z_{r} \\
c d t_{r} \\
Z_{w d} \\
N_{I F}^{s i}
\end{array}\right]
$$

The symbol $\nabla$ indicate the $L$ vector (observed minus computed values). The first three columns of the design matrix $A$ contain the derivatives in relation to station coordinates and represents the director cosine for the satellite-receiver vector. The mapping function for Zenithal wet troposphere is represented by $\mathrm{m}_{\mathrm{f}}$. The corrections for Cartesian coordinates are given by $\Delta \mathrm{X}_{\mathrm{r}}$, $\Delta \mathrm{Y}_{\mathrm{r}}$ and $\Delta \mathrm{Z}_{\mathrm{r}}$. The factor $\mathrm{c}$ represents the vacuum light velocity; the receiver clock is estimated as meters for numerical reason and the ambiguity in this case is obtained as float solution. Several researches nowadays attempt for ambiguity resolution as fixed in the PPP being known as mixed PPP-RTK, as can be seen for example in Laurichesse et al. (2008); Geng et al. (2011) and Teunissen and Khodabandeh (2015).

The relative positioning allows the Double Difference (DD) computation among observables from separated stations, which eliminate most of common errors involved with GNSS 
signal propagation as well as providing more feasible fixed ambiguity solution, mainly when considering short to medium baselines (Seeber, 2003; Leick, 2004). The DD equation for pseudorange and phase, considering short baselines and only a single frequency, can be written as (Seeber, 2003; Leick, 2004; Hofmann-Wellenhof; Lichtenegger; Wasle, 2008; Monico, 2008):

$$
\Delta P R_{i j}^{r s}=\Delta \rho_{i j}^{r s}+v_{P D_{i j}^{r s}}
$$

where $\Delta \rho_{i j}^{r s}=\rho_{i}^{r}-\rho_{j}^{r}-\rho_{i}^{s}+\rho_{j}^{s}$ and $v_{P D_{i j}^{r s}}$ represents, respectively, the combination of geometric distances and DD pseudorange residuals. Similarly, the DD phase combination can be written as:

$$
\Delta \phi_{i j}^{r s}=\frac{f}{c} \Delta \rho_{i j}^{r s}+\Delta N_{i j}^{r s}+v_{\phi_{i j}^{r s}}
$$

where $\Delta N_{i j}^{r s}=N_{i}^{r}-N_{j}^{r}-N_{i}^{s}+N_{j}^{s}$ is the double difference of ambiguity that is known to be an integer number and can be solved by mathematical approaches, as for example, the LAMBDA method (Teunissen, 1998). The unknown parameters involved in the relative positioning are the baseline components $(\Delta \mathrm{X}, \Delta \mathrm{Y}$ and $\Delta \mathrm{Z}$ ) and $\mathrm{DD}$ ambiguities (Hofmann-Wellenhof; Lichtenegger; Wasle, 2008; Monico, 2008).

The materials and methods used for the experiments are described in the next section.

\section{Materials and Methodology}

\subsection{Study Area and Currently Infrastructure Available}

The area under investigation is the Pernambuco state located in the northeast of Brazil and bathed by the Atlantic Ocean with coastal zone length around $187 \mathrm{~km}$. In the northern border are the limits with Paraiba state near Goiana city $\left(-07^{\circ} 33^{\prime} 50.0^{\prime \prime} ;-34^{\circ} 50^{\prime} 06.4^{\prime \prime}\right)$ and in the southern face with Alagoas state near São José da Coroa Grande (-08 $\left.48^{\prime} 33.2^{\prime \prime} ;-35^{\circ} 07^{\prime} 17.2^{\prime \prime}\right)$. Concerning the geodetic infrastructure available for positioning, the Brazilian user can apply data from GNSS Continuous Monitoring Brazilian Network (RBMC-IBGE). Further details about RBMC can be seen, for example, in the IBGE website (https://ww2.ibge.gov.br/home/geociencias/geodesia/rbmc/rb mc.shtm?c=7).

Currently there are more than 100 stations (Figure 2a) distributed along the Brazilian territory equipped with dual frequency receivers. Figure $2 \mathrm{~b}$ shows the RBMC stations distribution for the Pernambuco state and neighborhoods where the nearest station to the coastline is RECF located at Federal University of Pernambuco (UFPE) in the Recife city. The approximated minimum and maximum distances from RECF to the coastline is, respectively, of $10 \mathrm{~km}$ and $100 \mathrm{~km}$. Therefore, this framework configures long baselines for relative positioning estimation and hence PPP was the choice to attend the Pernambuco state law. 
Goncalves and Awange (2017) showed that PPP is an economical and feasible method being a reliable alternative for mapping and monitoring shorelines, however; it is recommended to analyze the PPP accuracy tracking long shoreline distances.

RBMC stations and RECF in the Pernambuco State, Brazil

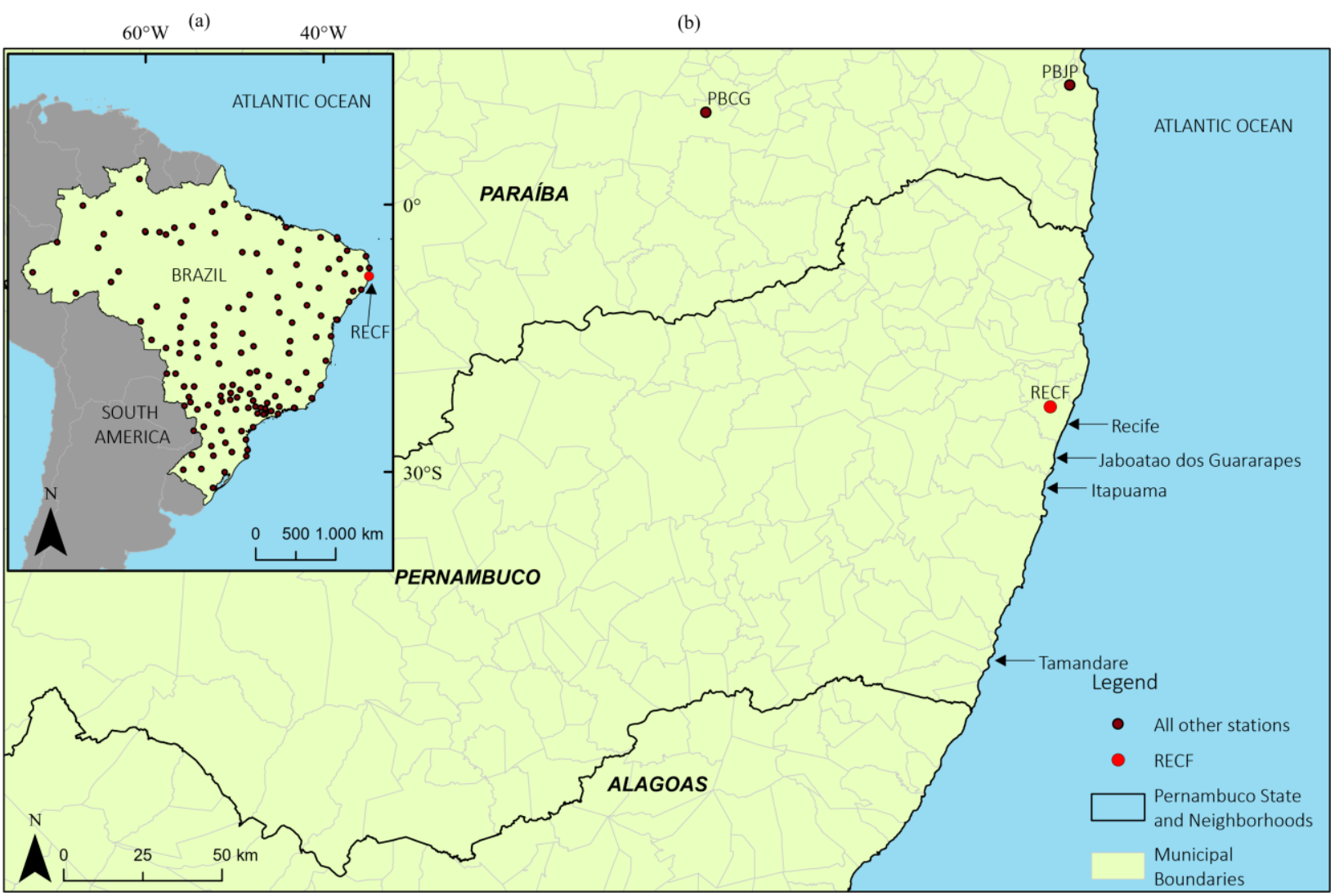

Figure 2: (a) Reference map of RBMC distributed along Brazilian territory (b) Pernambuco state and neighborhoods, where RECF station is located in Recife (capital of Pernambuco)

\subsection{Materials}

To carry out the kinematic shoreline survey, using 5 seconds rate and 10 degrees elevation mask, it was used a GS15/Leica (GPS and GLONASS) dual frequency receiver and the necessary accessories for e.g., batteries, chargers, computer, and collector. The data post processing for relative positioning was accomplished through Topcon Tools software licensed for UFPE. Vehicle coupled with GNSS receiver (see Figure $3(a)$ ) allowed the shoreline surveying. In some regions with difficult access, the surveyor walked carrying the receiver as shown in Figure 3 (b). 


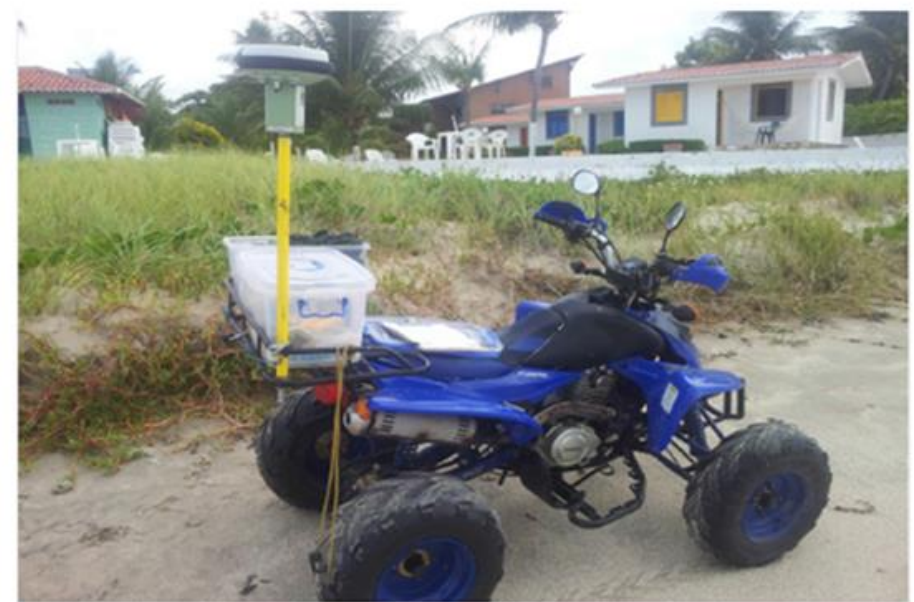

a)

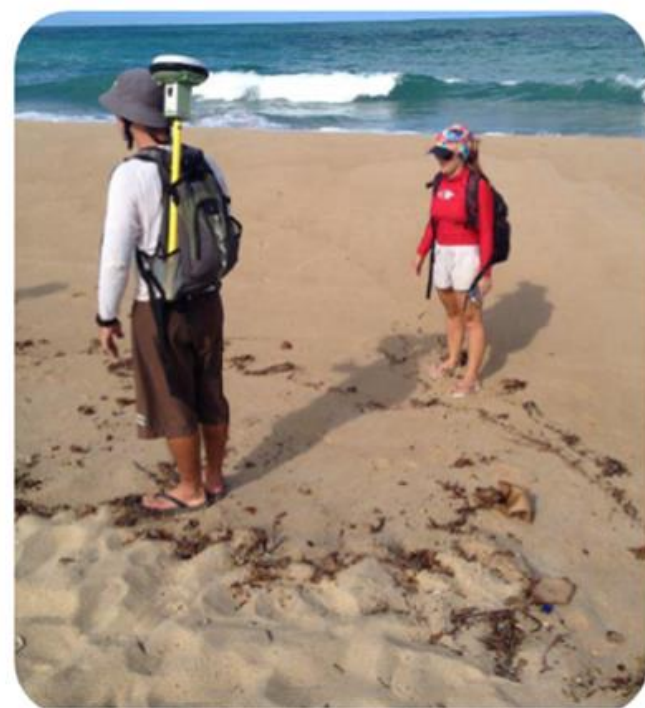

b)

Figure 3: Kinematic survey equipment. (a) Receiver connected to the quadricycle. (b) Field team on foot in places with difficult access.

GNSS data surveying was carried out during the spring high tide, which occurs in the new and full moon when the lunar and solar tides reinforce one another, producing the highest and lowest tides. In this case, the surveyor with experience about coastal geomorphology identify the shoreline trajectory in situ during the survey.

\subsection{PPP and Relative Kinematic Methods: Data Collection and Processing}

The PPP post-processing data was accomplished through the online tool from IBGE (http://www.ppp.ibge.gov.br/ppp.htm) which makes use of the CSRS-PPP software from Natural Resources of Canada (NRCAN). The CSRS-PPP is capable of processing GPS and GLONASS data in the static and kinematic PPP modes. The PPP post processing took account final precise orbits and clocks corrections from the International GNSS Service (IGS), with Troposphere Zenithal Wet Delay (TZWD) estimated as a random walk process ( $5 \mathrm{~mm} /$ hour). The precisions of $2 \mathrm{~m}$ and $0.02 \mathrm{~m}$ is assumed, respectively for the ionospheric free code and phase observables.

The Recife surrounding considering short baselines distances for relative positioning using RECF station (Figure 2) provided the reference values to evaluate PPP during convergence time periods. The minimum and maximum distances from shoreline to RECF station are approximately 10 and $20 \mathrm{~km}$, respectively. The relative positioning post processing used precise orbits and three types of ambiguity solution could be observed: partial, float and fixed (Teunissen, 1998). 


\subsection{Evaluation Criteria}

The PPP shoreline assessment considered the formal estimated precision, time convergence as well relative accuracy through Root Mean Square Error (RMSE) as expressed in equation 1.

$$
R M S E=\sqrt{\frac{\sum_{i=1}^{n} e_{i}^{2}}{n-1}}
$$

The residuals in equation 1 is written as $e_{i}=\dot{x}-x_{i}$ being $\dot{x}$ the reference value (average for example) and $x_{i}$ the observed value at epoch $i=1, \ldots, n$.

Positioning convergence concerns about enough time for coordinates estimation reaching a certain defined accuracy level (Abou-Galala et al., 2017). In general, around 30 to 60 minutes in order to achieve centimeter accuracy.

Several problems occurred when traversing the coastline as for example due to abrupt maneuver of quadricycle, places not accessible, interruptions of signal, etc. Such problems cause sometimes re-initialization of PPP processing or even wrong position estimation that were posterior detected and classified as outliers. The final shoreline was obtained after edition in a CAD (Computer Aided Design) software.

\section{Results and Discussion}

\subsection{Expected accuracy for kinematic PPP}

The raw GNSS data collected in the RECF station was processed in kinematic PPP considering interval data of 24 hours. Although we have data collected in a static reference stations, it was processed in the kinematic PPP. In this case, there are the possibility to analyze the expected PPP accuracy since the RECF position is well know from the SIRGAS network solution.

Figure 4 shows the formal coordinates precision (coming from variance matrix of the adjusted parameters) and discrepancies (also referred as 'errors') in the Geodetic Local System (GLS) when compared with known coordinates. The coordinates discrepancies (DE, DN and DU) are obtained by comparison with the official coordinates for RECF station divulged by IBGE, where the differences found in Cartesian system are converted to GLS (East, North and Up directions) with the proper propagation of uncertainties providing the SigDE, sigDN and SigDU (Seeber, 2003). Table 2 presents statistics for kinematic PPP in the static RECF station. 

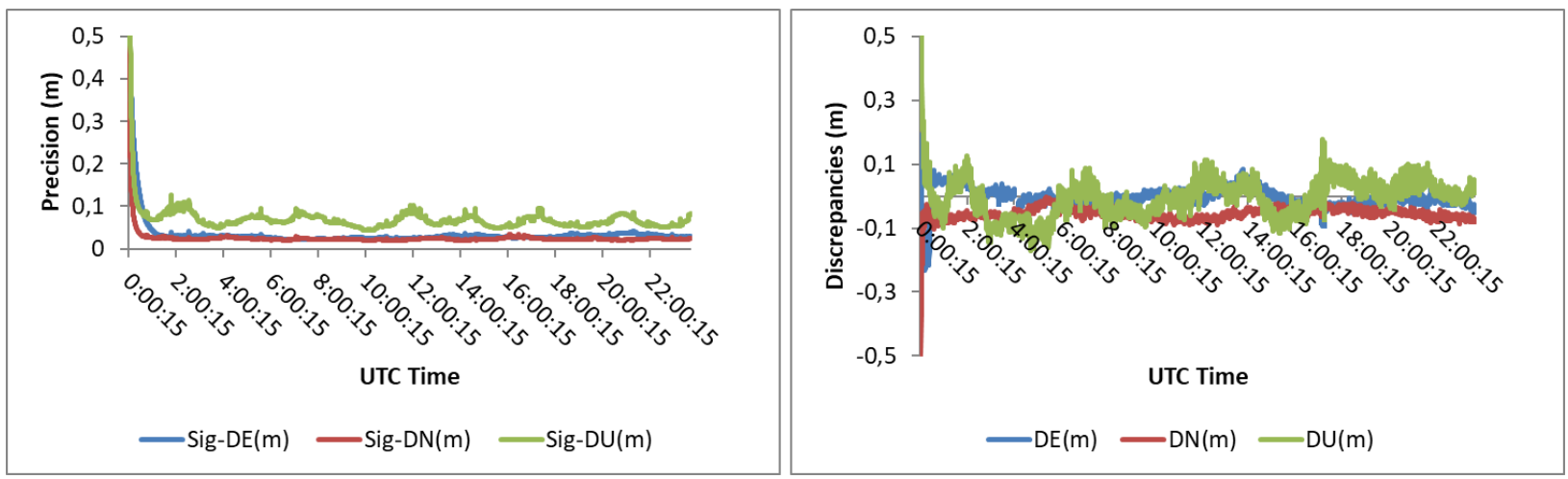

Figure 4: Estimated Precision (left) and discrepancies (right) for kinematic PPP in the RECF station

Table 2: Statistics ( $m$ ) for kinematic PPP for RECF station

\begin{tabular}{c|c|c|c|c|c}
\hline & $\mathrm{DE}$ & $\mathrm{DN}$ & $\mathrm{DU}$ & $2 \mathrm{D}$ & $3 \mathrm{D}$ \\
\hline Mean Error & -0.0051 & -0.0554 & 0.0003 & 0.0556 & 0.0556 \\
\hline Standard Deviation & 0.0395 & 0.0275 & 0.1518 & 0.0481 & 0.1593 \\
\hline RMSE & 0.0398 & 0.0618 & 0.1518 & 0.0735 & 0.1687 \\
\hline
\end{tabular}

Figure 4 shows that approximately one hour of collected data provides coordinate precision with values near centimeter in PPP processing, mainly for planimetric components. Discrepancies when comparing with RECF known coordinates reach values near $10 \mathrm{~cm}$ after the convergence period. The statistics presented in Table 2 shows RMSE values of near $7 \mathrm{~cm}$ and 16 $\mathrm{cm}$, respectively for planimetric (2D) and total resultant (3D), indicating expected accuracy of the order of decimeter for kinematic PPP for ideal situations.

\subsection{PPP shoreline precision}

Figure 5 presents latitude and longitude estimated precisions for shoreline PPP considering the extension between Itapuama and Jaboatao dos Guararapes (Figure 5a) and for a stretch in Tamandare (Figure 5b).

(a)

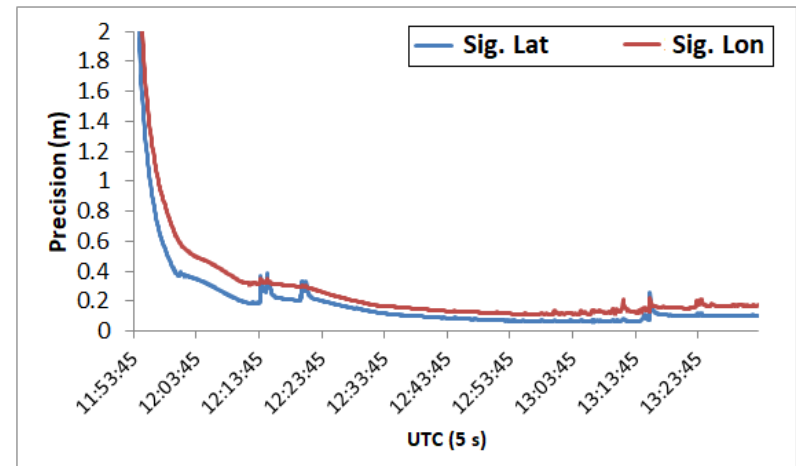

(b)

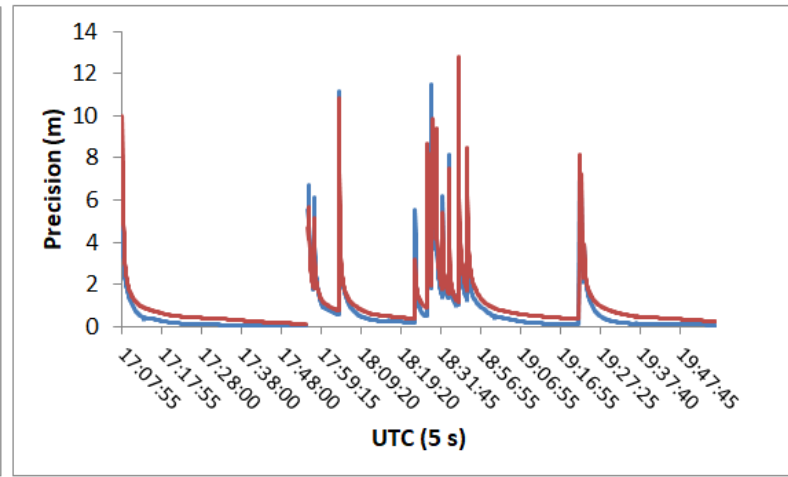

Figure 5: Shoreline estimated PPP precision: a) segment between Itapuama and Jaboatao dos Guararapes; b) segment near Tamandare. 
Figure 5a shows that PPP precision converged to values near $0.20 \mathrm{~m}$ in approximately 30 minutes. Such formal precision indicates that PPP attend the demand for shoreline determination. According to Douglas and Crowell (2000), the meaningful deduction was achievable even if the inherent variability of shoreline position indicators remained at the level of many meters. On the other hand, several surveying locations presented re-initialization of PPP positioning and it could be a challenge to avoid outliers, as can be seen in the sample for Tamandare (Figure 5b).

Although the precision time series presented several peaks, it is important to note the rapid re-convergence for decimeter level. The PPP re-initialization may occur due to several factors, as for example: cycle slips involving several satellites causing phase ambiguity parameters resets; GNSS receiver stop tracking satellites due to obstructions; abrupt quadricycle movements causing outliers detection in the processing, among others.

\subsection{Accuracy analysis between shoreline PPP and relative kinematic}

The accuracy analysis was accomplished by comparing PPP with relative kinematic method taking account short baselines between RECF and the surveyed shoreline during April 29 of 2014. For this purpose, four regions were selected and named, respectively, as sectors $A, B, C$ and D (see Figure 6) with data collecting time of approximately one hour for each sector. The main objective of using a short time span for GNSS data is to analyze the accuracy during the convergence period that usually takes around 1 hour for conventional PPP with float ambiguity solution as show, for example, in the section 5 -a. The length of the chosen sectors is of approximately $5 \mathrm{~km}$ and the average distances to the RECF base station are of $10 \mathrm{~km}, 8 \mathrm{~km}, 6 \mathrm{~km}$ and $5 \mathrm{~km}$, respectively for the sector $A, B, C$ and $D$.

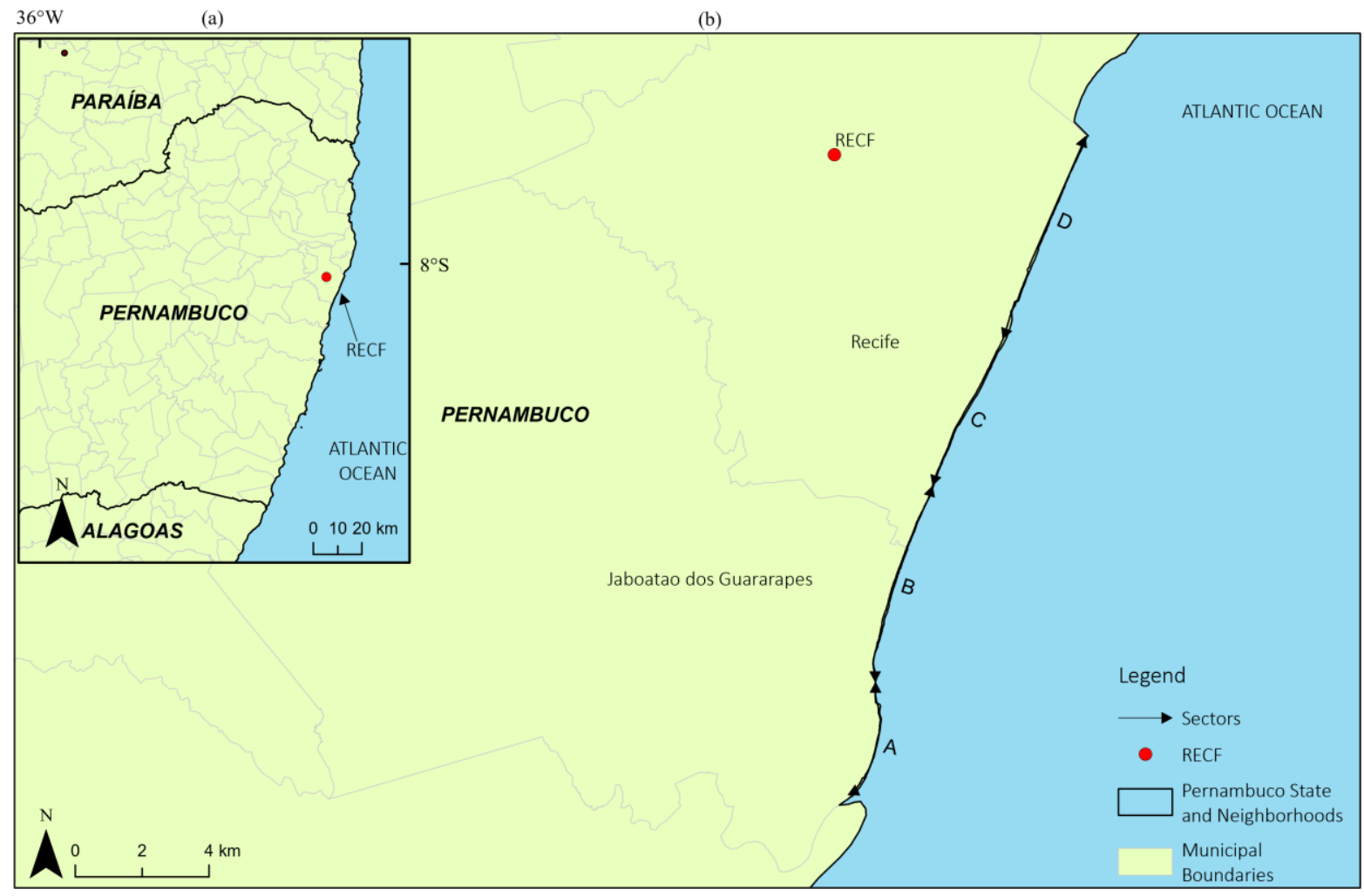

Figure 6: Sectors A, B, C and D near RECF aiming the PPP accuracy analysis with data collecting time of approximately one hour. 
The Figures 7 until 10 show the time series of precisions (SigLat, SigLon and SigH) for each sector and also show the differences (discrepancies) found among Relative and PPP coordinates (Dlat, Dlon, Dh and 2D).

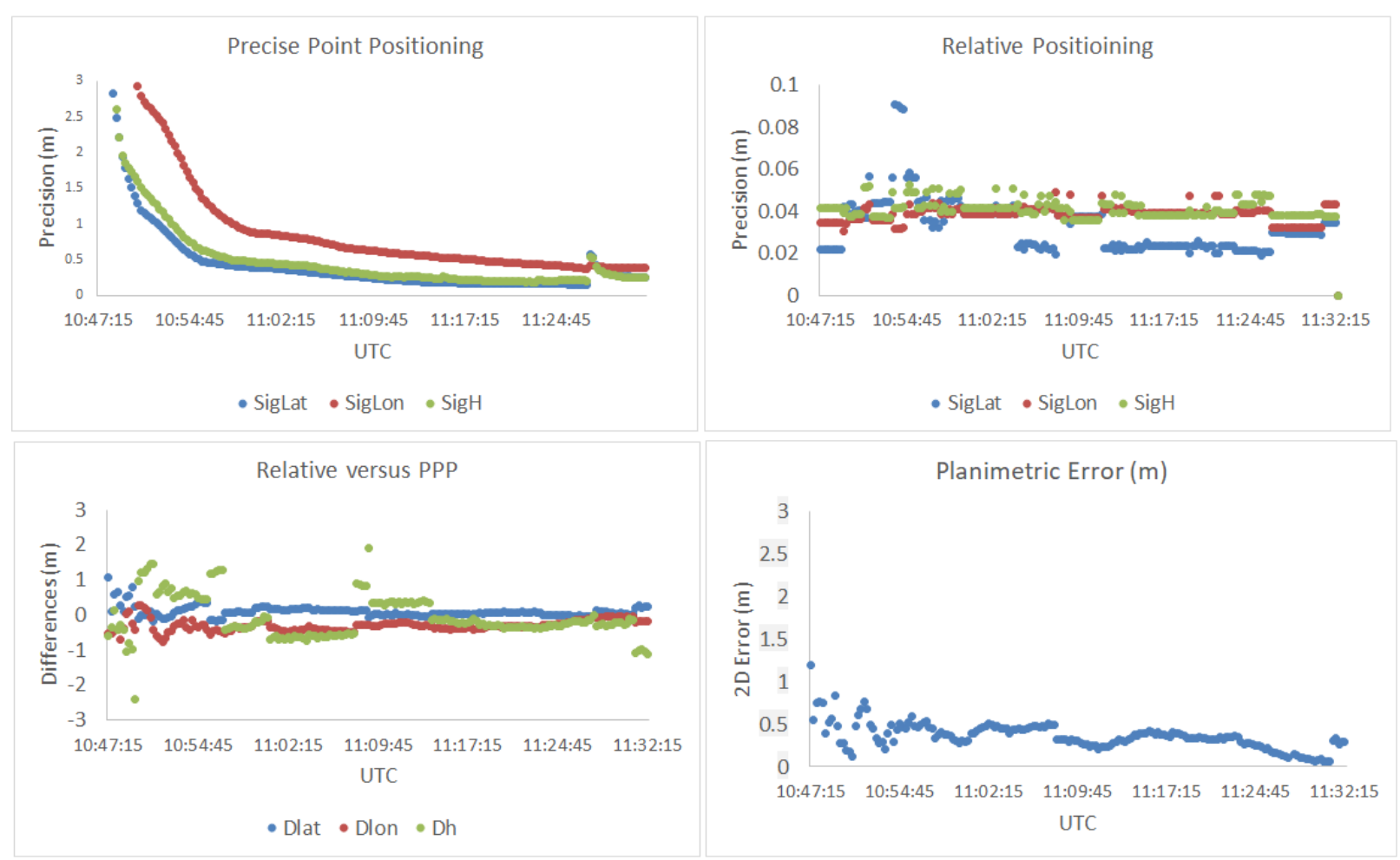

Figure 7: Time series precisions and discrepancies between relative and PPP for the sector A

The data collection for sector $A$ starts at 10:47:15 and finished 11:32:15 providing approximately one hour of data. From Figure 7, it could be seen that PPP precisions reach the order of $0.50 \mathrm{~m}$ after about 30 minutes of data processing. The precision in the relative positioning presents the order of $0.05 \mathrm{~m}$. The discrepancies reached values of the order of $0.50 \mathrm{~m}$ after few minutes and with one hour of data processing, the minimum planimetric error (2D error) found is of approximately $0.05 \mathrm{~m}$. 


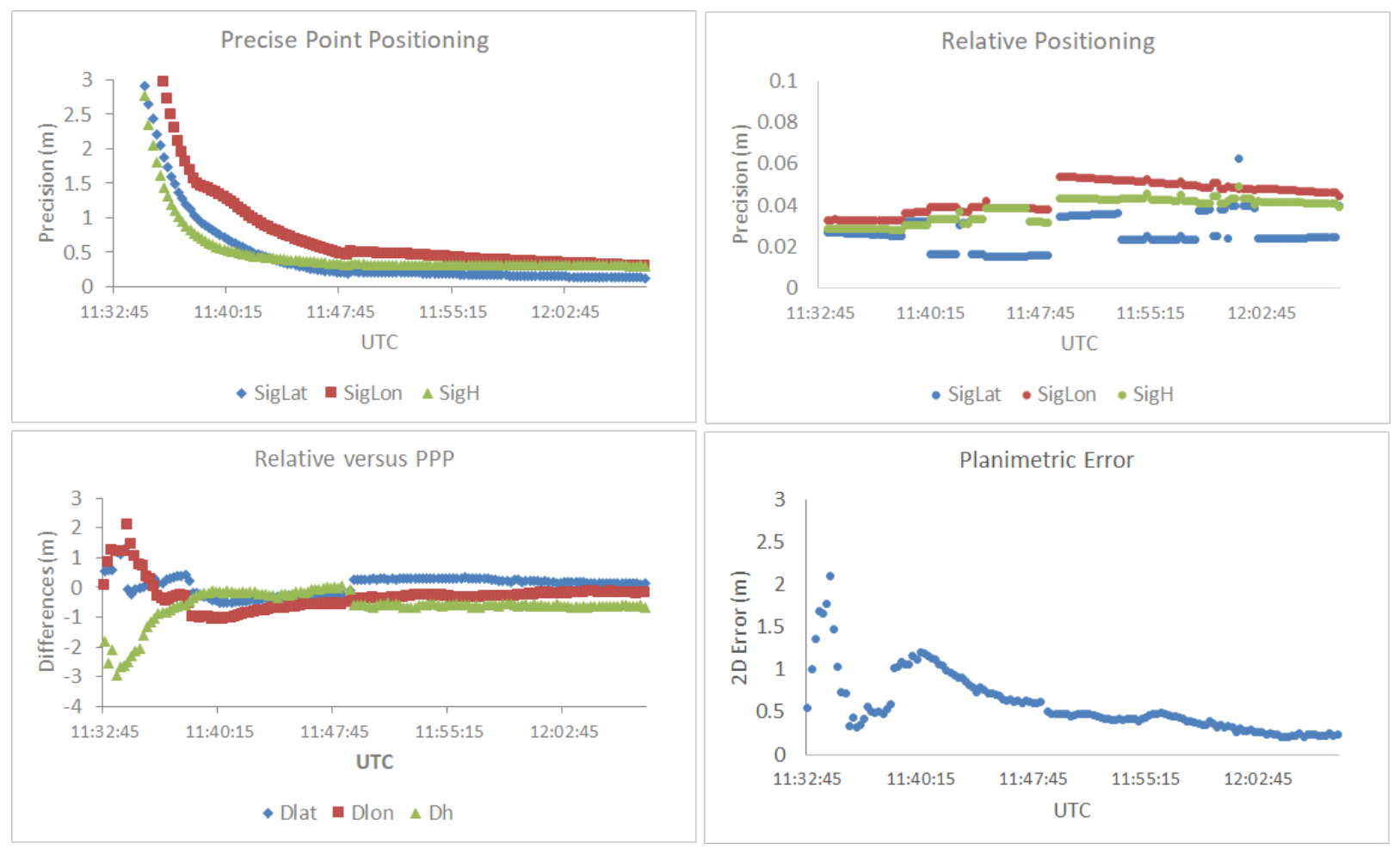

Figure 8: Time series precisions and discrepancies between relative and PPP for the sector B

The time span for the sector B is of approximately 36 minutes $(11: 32 \mathrm{~h}-12: 08 \mathrm{~h})$ and although re-initializations could be observed in the data processing, the planimetric error was of $0.23 \mathrm{~m}$ at the end of the sector as can be seen in the Figure 8 .

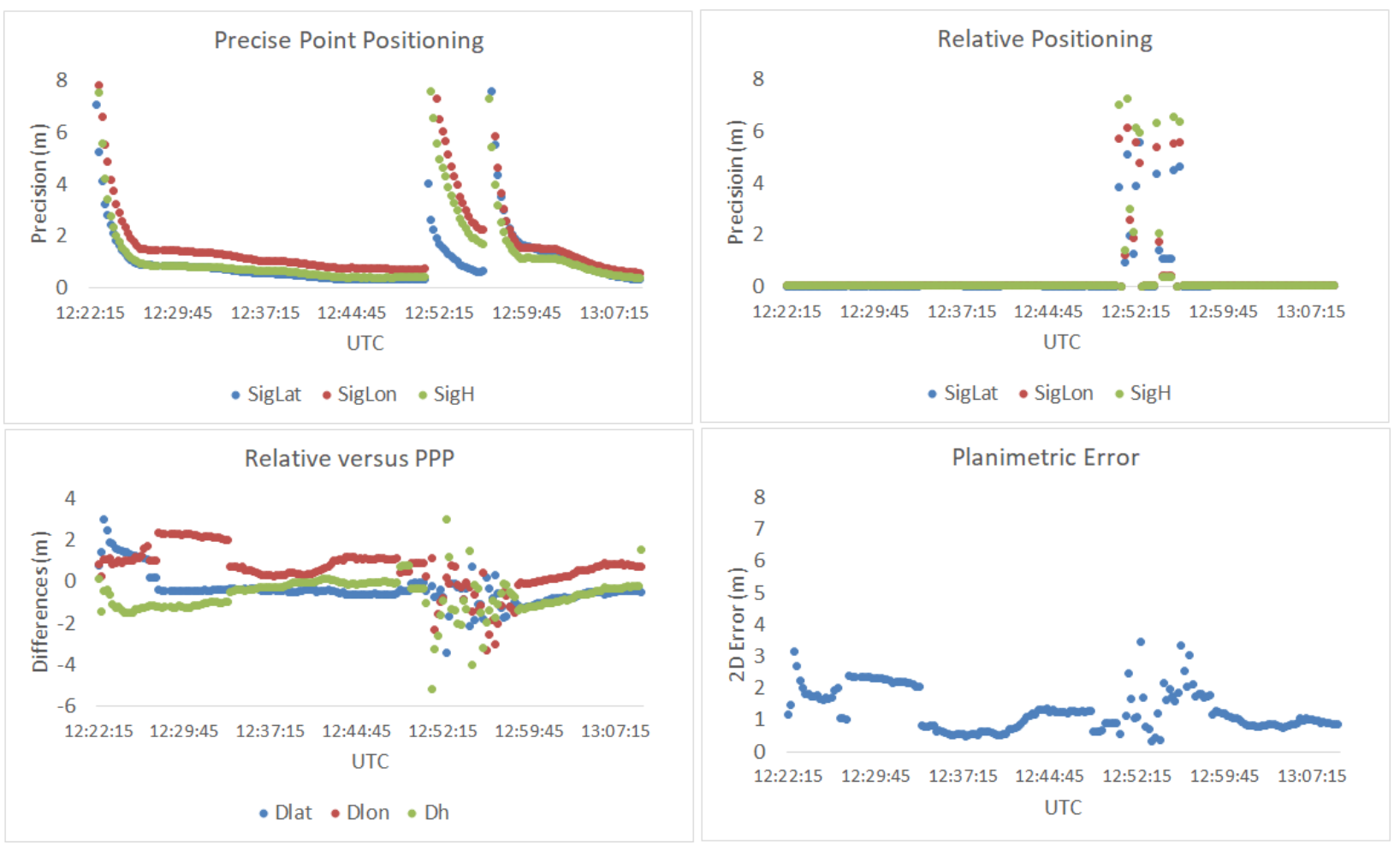

Figure 9: Time series precisions and discrepancies between relative and PPP for the sector $\mathrm{C}$ 
The data collection for the sector $\mathrm{C}$ start near 12:20 h with one hour of surveying as shown in the Figure 9. The PPP precisions converted to decimeter values after few minutes but severe re-initialization occurred after approximately 50 minutes of data processing. In this case, the planimetric error reached minimum value of about $0.50 \mathrm{~m}$ and in most of time the values is around $1 \mathrm{~m}$.

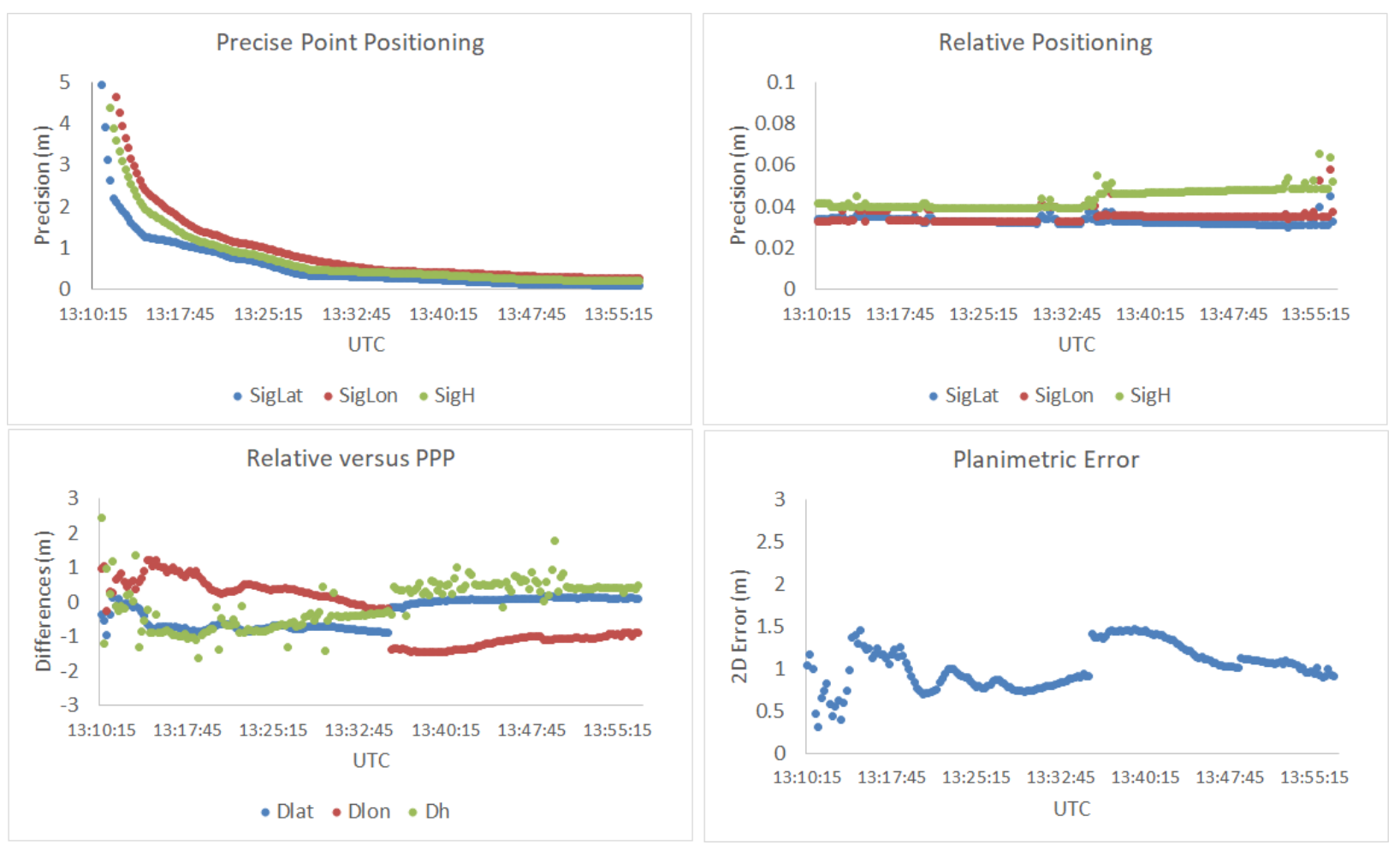

Figure 10: Time series precisions and discrepancies between relative and PPP for the sector D

As occurred in the sector $C$, re-initialization can be observed for the sector D (Figure 10) affecting the accuracy during the PPP convergence period. The time span of GNSS data collected in the sector $D$ is near 50 minutes and the values of planimetric error is around meters.

Considering the plots for all sectors presented in the Figures 7 until 10 the estimated PPP precision reached the order of $0.50 \mathrm{~m}$ after the convergence period (approximately 30 minutes). The sector $C$ showed the biggest resetting peak in the PPP positioning, that may be related to abrupt quadricyle maneuver, loss of satellite signals, cycle slips or other events.

The statistics (mean, standard deviation and RMSE) computed considering the entire data periods for each sector can be seen in the Table 3. 
Table 3: Statistics when comparing kinematic PPP and Relative during the convergence period.

\begin{tabular}{c|c|c|c|c}
\hline Sector & Component & Mean Error $(\mathrm{m})$ & Standard Deviation $(\mathrm{m})$ & RMSE (m) \\
\hline \multirow{4}{*}{ A } & Latitude & 0.089 & 0.156 & 0.180 \\
\cline { 2 - 5 } & Longitude & -0.313 & 0.160 & 0.352 \\
\cline { 2 - 5 } & Height & -0.056 & 0.586 & 0.589 \\
\hline \multirow{4}{*}{ B } & Latitude & 0.091 & 0.324 & 0.336 \\
\cline { 2 - 5 } & Longitude & -0.313 & 0.506 & 0.595 \\
\cline { 2 - 5 } & Height & -0.624 & 0.554 & 0.834 \\
\hline \multirow{4}{*}{ C } & Latitude & -0.385 & 0.763 & 0.854 \\
\cline { 2 - 5 } & Longitude & 0.609 & 1.000 & 1.171 \\
\cline { 2 - 5 } & Height & -0.658 & 0.842 & 1.069 \\
\hline \multirow{4}{*}{ D } & Latitude & -0.342 & 0.411 & 0.535 \\
\cline { 2 - 5 } & Longitude & -0.329 & 0.846 & 0.672 \\
\cline { 2 - 5 } & Height & -0.080 & 0.667 & \\
\hline
\end{tabular}

The maximum RMSE value (Table 3) was $1.17 \mathrm{~m}$ in longitude for the sector $\mathrm{C}$ and the minimum RMSE value was $0.18 \mathrm{~m}$ in Latitude for the sector A. The RMSE resulting for the planimetric components (latitude and longitude) are $0.39 \mathrm{~m}, 0.68 \mathrm{~m}, 1.45 \mathrm{~m}$ and $1.05 \mathrm{~m}$, respectively for sectors $A, B, C$ and $D$. These RMSE is in accordance with expected results for kinematic shoreline monitoring, even considering the analyses were carried out taking account the convergence period of the PPP. Conclusions and recommendations are provided in the next section.

\section{Conclusions}

This paper presented quality assessment of kinematic PPP for shoreline determination in the Pernambuco state aiming to comply with state law no. 14.258/2010 that establishes the State Policy of Coastal Management. The shoreline was defined for 2014 high tide and the GNSS surveying was carried out using dual frequency receiver coupled to a quadricycle covering approximately $187 \mathrm{~km}$.

The shoreline monitoring is crucial due to socioeconomic and environmental importance. The identification of the shoreline is not so trivial since it involves continental and oceanographic dynamics that is still subject to climatic and anthropic changes. The adopted method was the PPP considering that for the relative method the available RBMC station (RECF) is far hundreds of kilometers from the state border providing formation of long baselines. The application of the RTK method or new control stations requires greater investments while the PPP application could provide enough accuracy for shoreline monitoring making use of only one receiver. 
The analyses involved PPP convergence time and accuracy taking as reference, values from relative positioning for Recife region. The GNSS data processing in PPP mode was carried out using the online tool provided by IBGE and the estimated formal precisions reached approximately 0.20 $\mathrm{m}$ after convergence period that took around 30 minutes to one hour.

When comparing PPP against the relative positioning, the discrepancies reached the order of $0.50 \mathrm{~m}$ after convergence time. However, several positioning re-initializations occur degrading the accuracy to the meters order. The comparisons was accomplished for sectors near the RBMC station and considering data collection of about one hour, in order to assess the accuracy during the convergence period. The RMSE for the entire period in all sectors vary from near $0.18 \mathrm{~m}$ until $1.17 \mathrm{~m}$, respectively for Latitude and Longitude as shown in the section 4 .

Accuracy ranging from $0.20 \mathrm{~m}$ until approximately $1 \mathrm{~m}$ can be considered enough for shoreline monitoring since the final shoreline map is obtained after CAD edition, where normally outliers are detected and eliminated allowing the uniform shoreline recovering (Douglas and Crowell, 2000; Goncalves et al., 2012). The RMSE values found for the sample region indicate that the accuracy provided by the kinematic PPP method attend the demand for systematic shoreline monitoring, mainly in face of the terrestrial dynamic involved. It is important to emphasize that the PPP method application represents high productivity in terms of positional estimation and do not requires network GNSS near the shoreline.

However, due to several re-initializations observed in the positioning some recommendations may help for future works, as for example, to keep the vehicle in a static situation for some minutes before starting of shoreline surveying, in order to allows the PPP achieve the convergence. In any case, it is important to note that the IBGE PPP online tool does not allows the user to configure information for processing, e.g., the observable precisions for the stochastic model, the elevation cutoff value or others that could minimize the re-initializations and peaks in the time series of coordinates precisions. Considering the shoreline must be monitored at each five years, a good strategy for future works is to apply PPP processing tools that allow better interaction with users and also to attempt for modern application involving the PPP-RTK method with fix ambiguity resolution.

\section{Acknowledgement}

The authors would like to thanks the CNPq by financial support through processes 311545/2015-7 and 310412/2015-3 as well as FAPESP through process 2017/02968-3 and the agencies SEMAS and CPRH.

\section{Author's contribution}

Definition of research problem (R. M. GONÇALVES and P. S. PEREIRA), Literature review (H. A. MARQUES, R. M. GONÇALVES, A. S. ARAUJO and H. A. A. QUEIROZ), Definition of methodological procedures (H. A. MARQUES, R. M. GONÇALVES, H. A. A. QUEIROZ, A. S. ARAUJO and P. S. PEREIRA), Data collection (P. S. PEREIRA), Data processing (H. A. A. QUEIROZ, R. M. GONÇALVES, A. S. ARAUJO and H. A. MARQUES) Analysis and interpretation of data (H. A. MARQUES, R. M. GONÇALVES and H. A. A. QUEIROZ), Manuscript writing (H. A. MARQUES, R. M. GONÇALVES and H. A. A. QUEIROZ). 


\section{REFERENCES}

Abou-Galala, M., et al. 2017. Assessment of the accuracy and convergence period of Precise Point Positioning. Alexandria Engineering Journal (Print).

Alkan, R. M. et al. 2015 A comparative study for accuracy assessment of PPP technique using GPS and GLONASS in urban areas. Measurement, 69, pp. 1-8.

Asib A., Drakea, F.; Nawazb, R.; Woulds, C. 2018. Where is the coast? Monitoring coastal land dynamics in Bangladesh: An integrated management approach using GIS and remote sensing techniques, Ocean and Coastal Management Journal, 151, pp. 10-24.

Awange, J. L. 2012 Environmental monitoring using GNSS Global Navigations Satellite Systems, Springer, pp. 382.

Boak, E. H. and Turner, I. L. 2005. Shoreline definition and detection: A review, Journal of Coastal Research, 21(4). pp. 688-703.

Bracs, M. A. et al. 2016. Evaluation of opportunistic shoreline monitoring capability utilizing existing "surfcam" infrastructure. Journal of Coastal Research, 32(3), pp.542-554.

Cai, C and Gao, Y. 2007. Precise Point Positioning Using Combined GPS and GLONASS Observations, Journal of Global Positioning Systems, 1(11), pp. 13-22.

Cenci, L. et al. 2018. Integrating remote sensing and GIS techniques for monitoring and modeling shoreline evolution to support coastal risk management. GIScience \& Remote Sensing, 55(3), pp.355-375.

Clark, G. E. et al. 1998. Assessing the Vulnerability of Coastal Communities to Extreme Storms: The Case of Revere, MA., USA. Mitigation and Adaptation Strategies for Global Change, 3(1), pp. 5982.

Douglas, B. C., Crowell, M. 2000. Long-term shoreline position prediction and error propagation. Journal of Coastal Research 16 (1), pp. 145-152.

Faustino, R. C. 2006. Posicionamento Por Ponto Preciso estático e cinemático. Dissertação de mestrado. Universidade Estadual Paulista.

Geng, J., Teferle, F. N., Meng, X., Dodson, A. H. 2011. Towards PPP-RTK: Ambiguity resolution in real-time precise point positioning. Advances in Space Research, 47(10), pp. 0273-1177.

Goncalves, R. M. 2010. Modelagem de tendência a curto-prazo da linha de costa através de dados geodésicos temporais utilizando regressão linear, estimativa robusta a redes neurais artificiais. Tese de doutorado. Universidade Federal do Paraná.

Goncalves, R.M. et al. 2012. A comparison between three short-term shoreline prediction models. Ocean \& Coastal Management, 69, pp. 102-110.

Goncalves, R. M. Awange, J. and Krueger, C. P. 2012. GNSS-based monitoring and mapping of shoreline position in support of planning and management of Matinhos/PR (Brazil). Journal of Global Positioning Systems (Print), v. 11, pp. 156-168.

Goncalves, R. M. and Awange, J. 2017. Three Most Widely Used GNSS-Based Shoreline Monitoring Methods to Support Integrated Coastal Zone Management Policies. Journal of Surveying Engineering, 143, pp. 1-11. 
Hauschild, A. and Montenbruck, O. 2008. Kalman-filter-based GPS clock estimation for near real time positioning. GPS Solut. 13, pp. 173-182.

Hauschild, A. 2010. Precise GNSS Clock-Estimation for Real-Time Navigation and Precise Point Positioning. PhD - Technical University of Munich.

Hofmann-Wellenhof, B., Lichtenegger, H., Wasle, E. 2008. GNSS - Global Navigation Satellite Systems: GPS, GLONASS, Galileo, and more. Springer-Verlag Vienna, pp.518.

IBGE. 2015. Resolução da Presidência. R. PR n. 01/2015. Disponível em <ftp://geoftp.ibge.gov.br/metodos_e_outros_documentos_de_referencia/normas/rpr_01_2015 _sirgas2000.pdf>. Acesso em out. 2017.

Kaplan, E. D. and Hegarty, C. J. 2006. Understanding GPS: principles and applications. 2 ed. Boston: Artech House, pp. 683.

Kouba, J. 2009. Testing of global pressure/temperature (GPT) model and global mapping function (GMF) in GPS analyses. Journal of Geodesy, 83(3-4), pp. 199-208.

Laurichesse, D., Mercier, F., Berthias, J. P. 2008. Real time zero-difference ambiguities fixing and absolute RTK. ION NTM. San Diego, California.

Leandro, R. F. 2009. Precise Point Positioning With GPS: A New Approach for Positioning, Atmospheric Studies and Signal Analysis. PhD - University of New Brunswick.

Leick, A. 2004. GPS satellite surveying. 3rd. ed. New York. John Wiley \& Sons.

Li, R., DI, K., Ma, R. 2003. 3-D Shoreline Extraction from IKONOS Satellite Imagery. Marine Geodesy. 26, pp. 107-115.

Marques, H. A. 2012. PPP Em Tempo Real Com Estimativa Das Correções Dos Relógios Dos Satélites No Contexto De Rede GNSS. Tese de Doutorado - Faculdade de Ciências e Tecnologia, Universidade Estadual Paulista, Presidente Prudente.

Marques, H. A.; Monico , J. F. G.; Shimabukuro , M. H.; Oyama, R. T.; Wentz , J. P. 2014. PPP Em Tempo Real: Fundamentos, Implementação Computacional e Análises de Resultados no modo Estático e Cinemático. Revista Brasileira de Cartografia. 6(66/6).

Martins, K. A. et al. 2017. The influence of climate change on coastal erosion vulnerability in northeast Brazil. Coastal Engineering Journal, 128, pp. 071-125.

Mendonca, F. J. B. et al. 2014. Temporal Shoreline Series Analysis Using GNSS. Boletim de Ciências Geodésicas, 20, pp. 701-719.

Monico, J. F. G. 2008. Posicionamento pelo GNSS: Descrição, Fundamentos e aplicações. 2nd. ed. São Paulo. Editora UNESP.

Monico et al. 2009. Acurácia e Precisão: Revendo os Conceitos de Forma Acurada. Boletim de Ciências Geodésicas, 15(3), pp.469-483.

Moussaid, J. et al. 2015. Using automatic computation to analyze the rate of shoreline change on the Kenitra coast, Morocco. Ocean Engineering. 102, pp. 71-77.

Natesan, U. et al. 2015. Monitoring longterm shoreline changes along Tamil Nadu, India using geospatial techniques. Aquatic Procedia, 4, pp.325-332.

Seeber, G. 2003. Satellite Geodesy: Foundations, Methods and Aplications. 2nd. ed. Berlin-New York, pp. 589. Walter de Gruyter. 
Silva, L.M. et al. 2013. Modelagem fuzzy aplicada na detecção da vulnerabildade à erosão costeira. Boletim de Ciências Geodésicas, 19, pp. 746-764.

Teunissen, P.J.G. 1998. Quality control and GPS. In: Teunissen PJG, Kleusberg (ed) A GPS for Geodesy, 2nd. ed. Berlin, pp. 271-318. Springer-Verlag.

Teunissen, P. And Khodabandeh, A. 2015. Review and principles of PPP-RTK methods. Journal of Geodesy. 89 (3): pp. 217-240.

Turner, I. L. Harley, M. D. and Drummond, C.D. 2016. UAVs for coastal surveying. Coastal Engineering, 114, pp. 19-24.

Witchayangkoon, B. 2000. Elements of GPS precise point positioning. 2000. PhD. University of Maine, 265p.

Yigit, C. O. et al. 2016. The potential of GPS Precise Point Positioning method for point displacement monitoring: A case study, Measurement, 91, pp. 398-404. 